\title{
La evolución de las perífrasis verbales causativa e incoativa con poner en español: cambios de construcción y extensiones metafóricas
}

Marie Comer and Renata Enghels

Ghent University

\section{Sección 1: Introducción}

El verbo español poner se caracteriza por un intrincado perfil polisémico: siendo básicamente un verbo de colocación, expresa en primer lugar un desplazamiento de un tema hacia una nueva posición en el espacio (poner el mantel en la mesa) (Cifuentes Honrubia 1999; Ibarretxe 2012). Además de su significado prototípico locativo, la semántica de poner se extiende hacia el campo de la transferencia (poner una multa a alguien), funciona como verbo semi-copulativo (ponerse nervioso) y como verbo auxiliar en la construcción causativa (poner la leche a calentar) o incoativa (ponerse a llorar) (Comer, Enghels y Vanderschueren 2015). El presente estudio focaliza en el desarrollo de las perífrasis causativa $\left[\mathrm{SN}_{1}+\mathrm{V}+\mathrm{SN}_{2}+(\mathrm{a}+\mathrm{INF})\right]$ e incoativa $\left[\mathrm{SN}_{1}\right.$ $\left.+\mathrm{V}_{\text {pron }}+(\mathrm{a}+\mathrm{INF})\right]$, en las que poner funciona como verbo auxiliar ${ }^{1}$ gramaticalizado, combinándose con un complemento infinitivo subordinado. La perífrasis causativa se compone de dos subeventos: un sujeto principal $\mathrm{SN}_{1}$ que hace que (= evento 1) el sujeto subordinado $\mathrm{SN}_{2}$ realice el evento expresado por el infinitivo subordinado (= evento 2). En la perífrasis incoativa, el sujeto $\mathrm{SN}_{1}$ realiza él mismo el evento expresado por el infinitivo.

En lo relativo al campo de las perífrasis verbales en las lenguas romances, muchos son los lingüistas que se han volcado, desde una perspectiva sincrónica, en el estudio de las construcciones incoativas, a las que pertenece también [ponerse a + INF] (Gómez Torrego 1988;

\footnotetext{
${ }^{1}$ Es bien sabido que la categoría de los auxiliares se presta difícilmente a una definición unívoca (Lamiroy 1994: 70). En este estudio se utiliza el término 'auxiliar', siguiendo a Bosque y Demonte (1999: 2201 y 3373-3374), aunque otros autores prefieren hablar de 'semi-auxiliar' para distinguir verbos como poner de los auxiliares como haber (Borillo 2005).
} 
Gómez Manzano 1992; Lamiroy 1999; Llorente Vigil 1999; Fogsgaard 2001, 2002; Carrasco Gutiérrez et al. 2006; Verroens 2011; Aparicio et al. 2014 por citar algunos). En cambio, la amplia bibliografía dedicada a las perífrasis incoativas contrasta notablemente con la escasa literatura que trata de las construcciones causativas con poner, que no parecen haber despertado mucho interés científico. ${ }^{2}$ Es decir, muchos autores (entre otros García González 1992; Gómez Manzano 1992; Carrasco Gutiérrez 2006; García Fernández 2012) hacen caso omiso de ellas en sus obras dedicadas a las perífrasis verbales, mientras que otros (p.ej. Gómez Torrego 1988: 110111; Llorente Vigil 1999: 29) las excluyen explícitamente de la categoría de perífrasis ${ }^{3}$. En este artículo, no pretendemos entrar en esta cuestión, pero adoptaremos el término 'perífrasis' para ambas construcciones (la incoativa y la causativa). Forman ambas, siguiendo a la definición de la NGRAE (2009) 'combinaciones sintácticas en las que un verbo auxiliar incide sobre un verbo auxiliado, llamado a veces principal o pleno, construido en forma no personal' (un infinitivo en este caso). ${ }^{4}$ Además, en ambas construcciones - causativa e incoativa - poner funciona como

\footnotetext{
${ }^{2}$ Contrariamente a las construcciones causativas con hacer y dejar, llamadas factitivas (ver por ejemplo Enghels y Roegiest 2013 y las referencias allí citadas).

${ }^{3}$ Llorente Vigil (1999: 29) argumenta que en el uso causativo poner mantiene su significado de situar una cosa o persona en un lugar, y por tanto subsume que no está gramaticalizado (Luis pone a calentar la comida = Luis pone la comida para calentarla).

${ }^{4}$ Gómez Torrego (1988), García Fernández (2012) y Carrasco Gutiérrez et al. (2006) proponen varios criterios sintácticos para determinar si una construcción debe considerarse o no perifrástica. Constatamos que la construcción causativa cumple con algunos de los criterios formales, pero con otros no, por lo cual constituye un caso límite. Por un lado, se puede oponer que (a) la causativa no admite la subida de los clíticos (María puso a hervir el agua -> María la puso a hervir vs. *María puso a hervirla, Gómez Torrego 1988: 110-111), (b) no se combina con VV meteorológicos en la posición de auxiliado (*poner a alguien/algo a llover), y, (c) en el plano semántico no añade al conjunto un valor temporal, aspectual, modal o estilístico, propio de las perífrasis. Por el otro lado, sí cumple con los criterios siguientes: (a) no admite la sustitución por una completiva (*pongo a alguien que trabaje), (b) no puede entrar en una estructura ecuacional sin el uso del verbo hacer (comprarse un coche nuevo es lo que Juan pone a María *(a hacer)) y (c) tampoco admite la conmutación (pro)nominal (Juan pone a María a arreglar el jardín -> *Juan pone a María a esto/ello, *Juan pone a María al arreglo del jardín). Otros criterios, sin embargo, solo se cumplen parcialmente: si bien es cierto que el auxiliar poner no selecciona al sujeto o a los complementos, sino que lo hace el infinitivo (Juan pone a María a bailar vs. *La alfombra pone a María a bailar vs. *Juan pone a la alfombra a bailar), sí que impone ciertas restricciones en el sujeto principal: poner marca la tendencia a presentar sujetos animados con intención, precisamente, como consecuencia de su significado original de verbo de colocación. Concluimos que la construcción causativa es un caso límite de perífrasis: no es una perífrasis prototípica o ejemplar, pero tampoco conviene excluirla definitivamente de la categoría de las perífrasis. De ahí que, en nuestra opinión y si estamos en lo cierto, utilizamos el término 'perífrasis' para la construcción causativa en este artículo. Para más
} 
auxiliar: se acopla a un verbo infinito subordinado dejando así de funcionar como verbo principal (descategorialización), y pierde (en parte) su significado etimológico locativo (blanquemiento semántico parcial), como consecuencia de un proceso de gramaticalización (Lamiroy 1999) ${ }^{5}$.

Aun así, hasta la fecha falta una teoría que explique (a) en qué medida los usos de poner como auxiliar en las perífrasis causativas e incoativas se relacionan con su significado locativo prototípico, y (b) si y cómo se han desarrollado a partir de este significado léxico pleno, a través de un proceso de gramaticalización y una serie de cambios de construcción. Efectivamente, la bibliografía no contesta a estas preguntas de investigación, centrando la atención en las diferencias de uso entre las diversas perífrasis incoativas de una lengua (ej. ponerse $a$ vs. empezar/comenzar), o en el diferente grado de gramaticalización de las construcciones incoativas en las lenguas románicas (i.a. Lamiroy 1999; Lamiroy y De Mulder 2011), pero sin estudiar detenidamente su evolución diacrónica.

A ese respecto, tampoco constituye una excepción el estudio de Verroens (2011), que, para el verbo cognado francés mettre (mettre le café à chauffer, se mettre à travailler) reconstruye el proceso de gramaticalización en seis etapas diferentes, como muestra la Figura 1. Este esquema, que se basa en el modelo cuadripartito de Heine (2002), ha sido construido con base en datos sincrónicos del francés, y postula que mettre, en sus orígenes, tiene un significado fuente locativo: un agente hace que un tema cambie de lugar. En una segunda etapa intermedia, el tema se convierte en un ser animado, sin control sobre el proceso. Luego se añade un complemento

información sobre estas pruebas formales, véase Gómez Torrego (1988), García Fernández (2012) y Carrasco Gutiérrez et al. (2006).

${ }^{5}$ Cabe destacar que la pérdida del significado locativo sólo es parcial. La perífrasis causativa con poner supone 'situar' a una persona o una entidad en un lugar abstracto (es decir, una actividad, un proceso o un evento), por lo que se conserva de algún modo el significado locativo original del verbo. De la misma manera, la perífrasis incoativa con ponerse sitúa al agente o iniciador en el inicio de una actividad, un proceso o evento. Por lo tanto, se puede considerar que ponerse a su vez mantiene cierto significado locativo o referencial. El hecho de que estas construcciones se originen a partir de extensiones metafóricas del semantismo locativo, nos obliga a hablar de blanqueamiento semántico 'parcial' (Aparicio 2016; véanse también la Sección 4). 
infinitivo a la construcción locativa básica con tema animado: $\left[\mathrm{SN}_{1}+\mathrm{V}+\mathrm{SN}_{2}+\mathrm{LOC}+\mathrm{a}+\right.$ INF]. Este cambio sintáctico conlleva una ambigüedad semántica-interpretativa: (a) el agente hace el tema cambiar de lugar pero, (b) al mismo tiempo le hace iniciar una actividad expresada por el infinitivo. Luego, en una cuarta fase, el complemento locativo se hace superfluo y acaba por eliminarse, lo cual coincide con el surgimiento del uso causativo propiamente dicho del verbo $\left[\mathrm{SN}_{1}+\mathrm{V}+\mathrm{SN}_{2}+\mathrm{a}+\mathrm{INF}\right]$. En la quinta fase, en los contextos de cambio, el verbo entra en un esquema pronominal $\left[\mathrm{SN}_{1}+\mathrm{V}_{\text {pron }}+\mathrm{a}+\mathrm{INF}\right]$. El clítico se se reanaliza, pierde su autonomía y se hace parte integrante y obligatoria del verbo. Desaparece también la ambigüedad semántica: la construcción ya no puede interpretarse como locativa sino únicamente como perífrasis aspectual incoativa. Por fin, la construcción se mettre à + inf con valor incoativo se convencionaliza y como tal, el uso locativo y el uso incoativo pueden coaparecer en la misma oración. ${ }^{6}$ Como hipótesis de trabajo, aplicamos este modelo al desarrollo de poner (Figura 1).

Figura 1: Modelo de Verroens (2011) aplicado a poner

\begin{tabular}{|l|l|l|l|}
\hline \multicolumn{1}{|c|}{ Heine (2002) } & \multicolumn{1}{c|}{ Verroens (2011) } & \multicolumn{1}{c|}{ Hipótesis poner } \\
\hline Fase inicial & Fase 1 & Mettre quelque chose quelque part & Poner algo en un lugar \\
\hline Contexto puente & Fase 2 & Mettre quelqu'un quelque part & Poner a alguien en un lugar \\
\hline Fase 3 & $\begin{array}{l}\text { Mettre quelqu'un/un objet animé } \\
\text { quelque part à faire quelque chose }\end{array}$ & $\begin{array}{l}\text { Poner a alguien en un lugar a hacer } \\
\text { algo }\end{array}$ \\
\hline Contexto de cambio & Fase 5 & $\begin{array}{l}\text { Mettre quelqu'un à faire quelque } \\
\text { chose }\end{array}$ & Poner a alguien a hacer algo \\
\hline Convencionalización & Fase 6 & $\begin{array}{l}\text { Se mettre à mettre quelque chose } \\
\text { quelque part (bis) }\end{array}$ & Ponerse a hacer algo \\
\hline
\end{tabular}

Por tanto, el presente estudio persigue un doble objetivo:

1. verificar empíricamente la validez del modelo propuesto en la Figura 1 para la evolución de poner en español, y comprobar si y cómo las construcciones causativas e incoativas se han desarrollado a partir de la construcción básica de poner, en la que tiene un significado locativo léxico pleno;

\footnotetext{
${ }^{6}$ Ver también Garachana (2016: 139) y el concepto de heterosemia.
} 
2. fijar con más precisión el grado de gramaticalización de poner en la construcción causativa e incoativa: determinar en qué medida el verbo cumple con el papel de auxiliar, y en qué medida su evolución diacrónica señala un proceso de gramaticalización y/o construccionalización (Bergs y Diewald 2008; Trousdale 2008, 2010, Gisborne y Patten 2011; Traugott y Trousdale 2013).

\section{Sección 2: Corpus y metodología}

Para alcanzar estos objetivos, el artículo traza el desarrollo sintáctico y semántico de las perífrasis causativas e incoativas con poner entre el siglo 13 y el siglo 21 , y, además, compara los resultados de ambas construcciones con el fin de determinar si presentan un proceso evolutivo diacrónico similar.

El estudio diacrónico se basa en un amplio corpus compilado y anotado manualmente. Todas las construcciones incoativas y causativas de poner han sido extraídas de los bancos de datos Corpus Diacrónico del Español (CORDE) y Corpus del Español del Siglo XXI (CORPES XXI), en cinco períodos diferentes: los siglos $13,15,17,19$ y $21 .^{7}$ En total, como muestra la Tabla 1, el corpus cuenta con 6074 ocurrencias relevantes para este estudio.

\footnotetext{
${ }^{7}$ Para una discusión más detallada de las ventajas que ofrece el método de trabajar con cortes cronológicos e intervalos regulares, véase Jansegers (2015: 219-220) y Vergara Wilson (2009: 278; 286). Como CORPES XXI es un corpus lematizado, nos ha permitido recuperar con facilidad todas las ocurrencias de la conjugación entera de poner en el siglo 21. De estos resultados hemos sacado luego todas las construcciones causativas e incoativas pertinentes para el estudio actual. El CORDE, sin embargo, carece de una función lematizada, por lo cual, para los demás cortes cronológicos, todas las formas verbales del paradigma entero de poner han sido insertadas manualmente en el buscador, atendiendo a la ortografía moderna y antigua del verbo. Para conocer las conjugaciones verbales del español antiguo, varios diccionarios y gramáticas diacrónicas han sido consultados (Correas 1625; Azofra Sierra 2009; Penny 2012). Del uso causativo, todos los ejemplos del corpus han sido incluidos en el análisis. En cambio, el análisis del uso incoativo en los siglos 17, 19 y 21 se basa en un muestreo aleatorio de 200 ejemplos por siglo.
} 
Tabla 1: Frecuencias absolutas

\begin{tabular}{|c|c|c|c|}
\hline & Causativo & Incoativo & TOTAL \\
\hline $\mathbf{1 3}$ & 19 & $\mathbf{7}$ & 26 \\
\hline $\mathbf{1 5}$ & 128 & 115 & 243 \\
\hline $\mathbf{1 7}$ & 273 & 648 & 921 \\
\hline $\mathbf{1 9}$ & 327 & 1066 & 1393 \\
\hline $\mathbf{2 1}$ & 562 & 2929 & 3491 \\
\hline TOTAL & 1309 & 4765 & $\mathbf{6 0 7 4}$ \\
\hline
\end{tabular}

Los ejemplos han sido analizados para una variedad de parámetros que caracterizan con mayor detenimiento los rasgos sintácticos y semánticos de las construcciones. Se trata más concretamente de cuatro parámetros que, como será argumentado en este artículo, se definen como diagnósticas fiables del cambio lingüístico, y más en concreto de fenómenos de gramaticalización y auxiliarización:

1. la frecuencia relativa creciente (o decreciente) de la causativa e incoativa con poner, como indicio de una mayor (o menor) extensión de las construcciones;

2. el tipo de preposición que introduce el complemento infinitivo subordinado y que mide el grado de fijación formal de la construcción;

3. la posibilidad de intercalar elementos léxicos entre el verbo conjugado y el infinitivo, lo cual apunta a un grado de mayor o menor incorporación de ambos verbos y, pues, al grado de 'auxiliarización' del verbo principal;

4. los rasgos semánticos de los constituyentes principales de la construcción, a saber el sujeto principal agente $\left(\mathrm{SN}_{1}\right)$ y el sujeto subordinado paciente $\mathrm{SN}_{2}$, y el infinitivo subordinado. Este criterio permite estudiar en qué medida las construcciones se extienden a esquemas semánticos menos prototípicos, posiblemente más gramaticalizados.

Partiendo de estos parámetros y habida cuenta de los objetivos principales de este artículo, la investigación se desarrolla en cuatro fases. La sección 3 engloba concisamente las observaciones generales en lo que concierne a las frecuencias de los usos y su desarrollo histórico. Luego, las 
secciones 4 y 5 se dedican a la descripción de la evolución morfosintáctica de poner en los usos estudiados. Más concretamente, analiza la fijación formal de las dos construcciones (sección 4) y la incorporación sintáctica del verbo poner con su infinitivo (sección 5). La sección 6 se detiene en el estudio de la evolución semántica del verbo. La discusión final (sección 7) resume las conclusiones principales.

\section{Sección 3: Desarrollo cuantitativo de las construcciones causativa e incoativa}

Es generalmente aceptada la idea que la frecuencia creciente de una unidad lingüística es un indicador importante de un cambio lingüístico. Thomson y Mulac (1991: 319), por ejemplo, afirman que el aumento en la frecuencia de un elemento es un indicio importante de su gramaticalización. El mismo razonamiento ha sido aplicado a la formación de nuevas construcciones por Traugott y Trousdale (2013: 18): 'When new constructions are formed they typically "spread by gradually increasing their frequency of use over time" (Bybee and McClelland 2005: 387),'

La Tabla 2 reúne las frecuencias relativas (es decir por cada 10.000 ocurrencias del verbo poner en los bancos de datos consultados) de las perífrasis causativas e incoativas. 
Tabla 2: Frecuencias relativas

\begin{tabular}{|c|c|c|}
\cline { 1 - 1 } perífrasis & \multirow{2}{*}{ causativa } & \multirow{2}{*}{ incoativa } \\
\cline { 1 - 1 } s. & & 7 \\
\hline 13 & 19 & 27 \\
\hline 15 & 30 & 112 \\
\hline 17 & 47 & 277 \\
\hline 19 & 85 & 509 \\
\hline 21 & 98 & \\
\hline
\end{tabular}

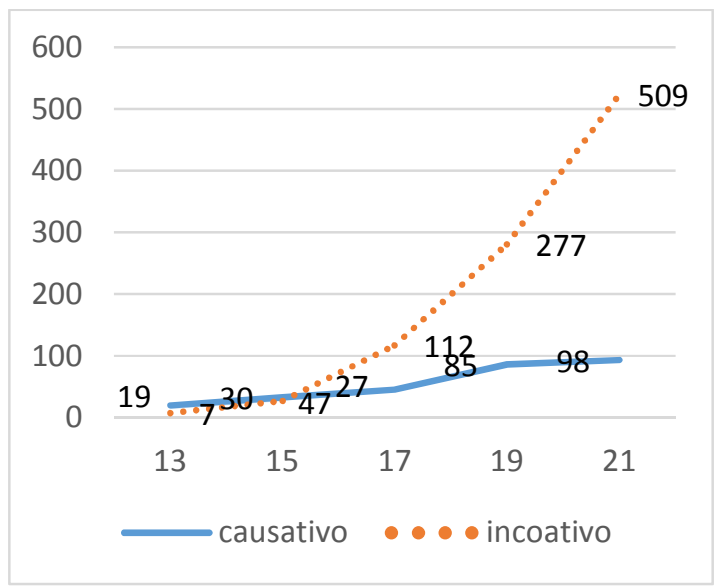

El gráfico muestra que el desarrollo del uso incoativo de poner se caracteriza por una subida fuerte y continua de su frecuencia relativa desde el siglo 13 hasta la época actual. En cambio, la frecuencia de uso de la construcción causativa con poner aumenta más paulatinamente, aunque al inicio predominaba cuantitativamente al uso incoativo (19 vs. 7). Estas primeras observaciones cuantitativas sugieren un posible grado de gramaticalización más elevado de poner en la incoativa y, por extensión, de la construcción incoativa entera comparada a la construcción causativa. Esta hipótesis se analiza más en detalle en las secciones siguientes.

Para llevar a cabo este estudio, atendemos primero al proceso evolutivo formal seguido por las perífrasis causativas e incoativas. Más concretamente, dos parámetros permiten examinar en qué medida ambas construcciones dan muestras de una gradual fijación morfosintáctica, a saber la preposición que se utiliza para encabezar el complemento infinitivo subordinado (sección 4), y el grado de incorporación entre poner y el verbo subordinado (el infinitivo) (sección 5).

\section{Sección 4: Fijación de la forma: $a+i n f$ vs. $e n+i n f$}

Ante todo, resulta interesante estudiar el tipo de preposición que precede al complemento infinitivo en ambas perífrasis. A ese respecto, llama la atención que el CORDE no solo atestigua ejemplos con la preposición $a$, sino también varios con la preposición en. De hecho, tanto en la 
construcción causativa (1a-b) como en la construcción incoativa (2a-b) destacan varias alternancias entre en y $a$ con el mismo infinitivo subordinado. Asimismo en los ejemplos más antiguos (ante todo de los siglos 13 y 15) de ambas construcciones falta a veces cualquier preposición entre poner y el infinitivo subordinado (3a-b):

(1) a. "Señor," rrespondyó el cantor, "es la más mala persona del mundo, y no tyene cabe sy syno ladrones y rrufyanes y gente que le ponga en hazer mal, y en muchas desonestydades, y por cyerto que anoche en la cámara hablavan de vos. ([CORDE]: Anónimo, La corónica de Adramón, s.15)

b. "Señor Octavio, esto he hecho por divertiros; el celo se me agradezca, que osadía ha sido poner a hacer esto delante de quien tantas voces mejores que la mía habría oído" ([CORDE]: Castillo Solórzano, Alonso de, La garduña de Sevilla , s.17)

(2) a. tal diligençia ha puesto vuestra señoría en procurar esta escritura mía, no dina de ser procurada, de creer es que mucho mejor se porná en aver y leer otras mejores en materias y más elegantes en la forma. ([CORDE]: Manrique, Gómez, Introducción [Cancionero de Gómez Manrique], s.15) b. ¿Qué pareciera que un pastor, que en su vida ha salido de guardar ganado, se pusiera a leer teología sin haber estudiado letra? ([CORDE]: Santos, Francisco, Día y noche de Madrid, s.17)

(3) a. Entonces don Illán dio voces, llamando la criada y mandóle que pusiese asar las perdices ([CORDE]: Gracián, Baltasar, Agudeza y arte de ingenio, s.17)

b. Aguardé buen rato, quitéme la capa y sombrero, y poniéndolo sobre una silla, muy despacio me puse considerar las desdichas a de algunos hombres. ([CORDE]: Alcalá Yáñez y Ribera, Jerónimo, El donado hablador Alonso, mozo de muchos amos. Primera parte, s.17)

Sin embargo, las frecuencias de las preposiciones en cada siglo estudiado (Tabla 3) revelan un aumento continuo de la preposición $a$, en detrimento de la preposición en y de los casos 'cero' (desprovistos de preposición), para ambas construcciones. Efectivamente, en las causativas e 
incoativas en español actual, el uso de $a$ se ha generalizado mientras que en y cero no aparecen en el muestreo del siglo 21.

Tabla 3: Variación preposiciones

\begin{tabular}{|c|c|c|c|c|c|c|c|c|c|c|c|c|c|c|c|c|}
\hline \multirow{3}{*}{$\begin{array}{c}\text { perífrasis } \\
\text { s. }\end{array}$} & \multicolumn{8}{|c|}{ causativa } & \multicolumn{8}{|c|}{ incoativa } \\
\hline & \multicolumn{2}{|c|}{ en } & \multicolumn{2}{|c|}{$\mathrm{a}$} & \multicolumn{2}{|c|}{ cero } & \multicolumn{2}{|c|}{ total } & \multicolumn{2}{|c|}{ en } & \multicolumn{2}{|c|}{$\mathrm{a}$} & \multicolumn{2}{|c|}{ cero } & \multicolumn{2}{|c|}{ total } \\
\hline & \# & $\%$ & \# & $\%$ & \# & $\%$ & \# & $\%$ & \# & $\%$ & \# & $\%$ & \# & $\%$ & $\#$ & $\%$ \\
\hline 13 & 3 & 15,8 & 13 & 68,4 & 3 & 15,8 & 19 & 100 & 4 & 57,1 & 3 & 42,9 & 0 & 0 & 7 & 100 \\
\hline 15 & 9 & 7 & 111 & 86,7 & 8 & 6,3 & 128 & 100 & 12 & 10,4 & 102 & 88,7 & 1 & 0,9 & 115 & 100 \\
\hline 17 & 6 & 2,2 & 265 & 97,1 & 2 & 0,7 & 273 & 100 & 8 & 4 & 191 & 95,5 & 1 & 0,5 & 200 & 100 \\
\hline 19 & 1 & 0,3 & 324 & 99,1 & 2 & 0,6 & 327 & 100 & 1 & 0,5 & 199 & 99,5 & 0 & 0 & 200 & 100 \\
\hline 21 & 0 & 0 & 562 & 100 & 0 & 0 & 562 & 100 & 0 & 0 & 200 & 100 & 0 & 0 & 200 & 100 \\
\hline
\end{tabular}

Así pues, en lo que concierne a la preposición, la construcción causativa e incoativa presentan una evolución paralela: en los siglos 13 y 15 se observa más variabilidad sintáctica, visto que las construcciones podían formarse con $a$, en o sin preposición alguna. Los datos cuantitativos muestran que en una fase posterior (sobre todo a partir del siglo 17) tiene lugar una fijación formal de ambas perífrasis verbales que consiste en el uso exclusivo de la preposición $a$, y la extinción de las variantes con en y cero. ${ }^{8}$

Ahora bien, estas observaciones nos fornecen importantes indicios, y tal vez la clave, para explicar cómo ambas construcciones perifrásticas se han desarrollado a partir del uso locativo básico de poner. En concreto, alegamos que las perífrasis verbales causativa e incoativa con poner se han formado a través de una extensión metáfora del esquema locativo de movimiento causado (caused-motion) propuesto por Goldberg (1995:52) e ilustrado mediante la Figura 2.

\footnotetext{
${ }^{8}$ La variabilidad sintáctica encontrada es conforme a las observaciones de Cano Aguilar (1977-78: 336), quien afirma que "en castellano medieval existen numerosas fluctuaciones en el empleo de las preposiciones", y esto en parte porque el sistema no estaba aún completamente fijado.
} 
Figura 2: Esquema de movimiento causado aplicado a put (poner) (Goldberg 1995:52)

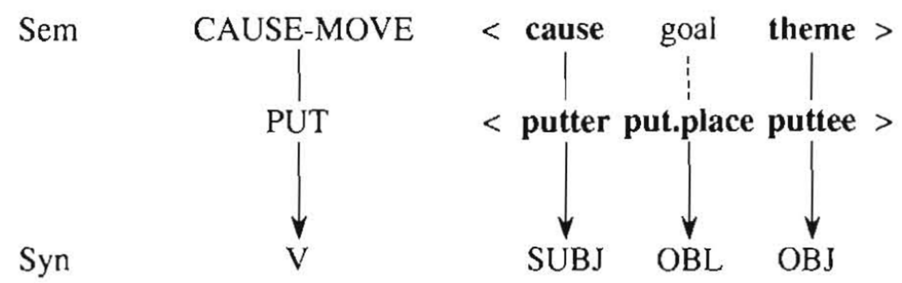

De acuerdo con este esquema básico, una causa (el sujeto-agente) hace que un tema (prototípicamente el OD) se desplace a otro lugar en el espacio (la meta, expresada mediante un complemento oblicuo prototípicamente introducido por la preposición en en español). Los ejemplos del corpus de tipo (1a, 2a) en que el complemento infinitivo se introduce mediante la preposición en sugieren que, a partir de este esquema básico de movimiento causado, otro subesquema ha surgido en el que un participante (P1) pone a otro participante (P2) en un lugar abstracto, in casu el evento o proceso subordinado expresado por el infinitivo. Así, en (1a) la gente $(\mathrm{P} 1)$ pone a una persona expresada con el clítico dativo le $(\mathrm{P} 2)$ en el proceso de hacer malas cosas $(e n+I n f)$. Paralemente en (2a) el participante P1 vuestra señoría pone a sí mismo en el estado de aver mejores escrituras y en la actividad de leerlas $(e n+I n f)$. Nótese que en (1a) el complemento en + Inf coocurre con en + frase nominal abstracta (en muchas desonestydades) que corrobora la extensión metafórica de 'poner una entidad en un lugar concreto' a 'poner una entidad en un lugar abstracto' que puede interpretarse como un evento o un proceso. En las variantes $(1 \mathrm{~b}, 2 \mathrm{~b})$ la preposición $a$ indica que el hablante conceptualiza el proceso expresado por el infinitivo, hacer esto y leer teología, como un objetivo por alcanzar en un futuro inmediato. En otras palabras, de acuerdo con su significado básico, la preposición $a$ expresa finalidad. Luego, después de este periodo de competición entre tres variantes formales, la construcción que sea más compatible con el significado global de las perífrasis verbales causativa e incoativa, a saber la 
variante con preposición final $a$, se hace predominante y contribuye a la extinción de las demás (véase también Cano Aguilar 1977-78: 370 y la nota 8).

Postulamos, pues, que una extensión metafórica del esquema básico del movimiento causado se encuentra en la base del uso de las perífrasis verbales causativa e incoativa en el español actual. Los datos confirman así el papel fundamental de la metáfora PONER EN UN LUGAR CONCRETO -> PONER EN UN LUGAR ABSTRACTO -> PONER EN UN EVENTO/PROCESO/ESTADO COMO motor del cambio lingüístico (Traugott y Dasher 2002; Jansegers y Enghels 2013, entre otros). Sin embargo, como ya sugieren los datos mencionados, este cambio semántico conlleva una serie de cambios construccionales que estudiamos en la sección 5.

\section{Sección 5: Fijación de la forma: el grado de incorporación sintáctica}

Por todo lo expuesto en la sección anterior, conviene examinar en qué medida ha tenido lugar una fijación formal adicional de las perífrasis verbales bajo estudio. El punto de partida radica en que si, después del cambio semántico principal descrito en la sección anterior, poner se gramaticaliza hasta adquirir el estatus de auxiliar, gradualmente tendría que incorporarse más con el complemento de infinitivo que sigue. Desde el punto de vista sintáctico, la incorporación se define como la unión (Fauconnier 1983) o composición de un verbo principal y otro subordinado en un predicado complejo. Como consecuencia, ningún elemento léxico se intercala entre ambos verbos fusionados (Enghels 2007: 150). La aplicación de esta definición a nuestro objeto de estudio conduce a la siguiente hipótesis de trabajo: cuanto más frecuentemente y cuanto más elementos léxicos se encuentran entre poner y su infinitivo, más bajo será el grado de incorporación, y menos indicios habrá para corroborar la gramaticalización de poner como auxiliar en una construcción compuesta. Y al revés, la contigüidad entre dos verbos puede 
apuntar a un grado más alto de incorporación y con ello la formación de un predicado complejo (Fischer 2007: 193).

Por consiguiente, en los ejemplos (4a-b) no se intercala ningún elemento léxico (salvo la preposición $a$ ) entre poner y el infinitivo subordinado, lo cual sugiere un grado de incorporación posiblemente más alto de las construcciones causativas e incoativas, en comparación con los casos en (5a-b). En la causativa (5a) se intercala tanto un complemento adverbial muchas vezes como el participante subordinado sus doctas manos entre ambos predicados; en la incoativa (5b) se observa intercalación del complemento adverbial tan presto. Esto sugiere una mayor autonomía sintáctica (y semántica) de ambos predicados, y, en consecuencia, una fase menos avanzada en el proceso de incorporación y auxiliarización de poner.

(4) a. Sabida la pronunciación de esto, pondrán a leer al discípulo, diciéndole que vaya nombrando las letras aprisa [...]. ([CORDE]: Bonet, Juan Pablo, Reducción de las letras y arte para enseñar a hablar los mudos, s.17 )

b.Ocasionado del camino, cansado y fatigado, se pone a pensar muchas veces muy a lo vivo en todos los caminos que Dios hombre por su bien y reparo hizo. ([CORDE]: San Juan Bautista de la Concepción, Un breve tratado para los hermanos donados, s.17)

(5) a. [...] que puso muchas vezes sus doctas manos a scriuir el verso heliconio ([CORDE]: Anónimo, De las mujeres ilustres en romance, 15th c.)

b. [...] que de otra manera no me pusiera tan presto a sumar la cuenta de mi lavor y trabajo ([CORDE]: Encina, Juan del, Proemio [Cancionero], s.15)

De acuerdo con este razonamiento, la Tabla 4 muestra las frecuencias de las construcciones con y sin elementos intercalados entre poner y el complemento infinitivo. 
Tabla 4: Intercalación elementos léxicos entre poner e infinitivo

\begin{tabular}{|c|c|c|c|c|c|c|c|c|c|c|c|c|}
\hline \multirow{3}{*}{$\begin{array}{c}\text { perífrasis } \\
\text { s. }\end{array}$} & \multicolumn{6}{|c|}{ causativa } & \multicolumn{6}{|c|}{ incoativa } \\
\hline & \multicolumn{2}{|c|}{$\begin{array}{l}\text { + elemento } \\
\text { intercalado }\end{array}$} & \multicolumn{2}{|c|}{$\begin{array}{l}\text { - elemento } \\
\text { intercalado }\end{array}$} & \multicolumn{2}{|c|}{ total } & \multicolumn{2}{|c|}{$\begin{array}{l}\text { + elemento } \\
\text { intercalado }\end{array}$} & \multicolumn{2}{|c|}{$\begin{array}{l}\text { - elemento } \\
\text { intercalado }\end{array}$} & \multicolumn{2}{|c|}{ total } \\
\hline & \# & $\%$ & $\#$ & $\%$ & $\#$ & $\%$ & \# & $\%$ & \# & $\%$ & \# & $\%$ \\
\hline 13 & 9 & 47,4 & 10 & 52,6 & 19 & 100 & 2 & 28,6 & 5 & 71,4 & 7 & 100 \\
\hline 15 & 58 & 45,3 & 70 & 54,7 & 128 & 100 & 14 & 12,2 & 101 & 87,8 & 115 & 100 \\
\hline 17 & 162 & 59,3 & 111 & 40,7 & 273 & 100 & 20 & 10 & 180 & 90 & 200 & 100 \\
\hline 19 & 61 & 18,7 & 266 & 81,3 & 327 & 100 & 19 & 9,5 & 181 & 90,5 & 200 & 100 \\
\hline 21 & 177 & 31,5 & 385 & 68,5 & 562 & 100 & 11 & 5,5 & 189 & 94,5 & 200 & 100 \\
\hline
\end{tabular}

De los datos cuantitativos se desprende que, si comparamos los diferentes cortes cronológicos, contrariamente a las expectativas, la frecuencia de ejemplos intercalados entre poner y el infinitivo en la construcción causativa no baja notablemente. En el siglo 21, todavía el 31.5\% del muestreo analizado cubre ejemplos con intercalación, es decir sin incorporación (6). En cambio, en la construcción incoativa el número de ejemplos con intercalación señala más claramente una tendencia a la baja. En el español contemporáneo casi ya no se intercalan elementos entre la unidad [ponerse $+\mathrm{a}+\mathrm{INF}$ ] (compárense los ejemplos $7 \mathrm{a}$ y $7 \mathrm{~b}$ sin y con intercalación del adverbio también). Estos resultados sugieren un estatus más gramaticalizado de poner como auxiliar incoativo comparado a su uso en la construcción con significado causativo.

(6) Alemania ha puesto al mundo a temblar. ([CORPES XXI]: Público, s.21)

(7) a. Junto a los bancos desde primera hora de la mañana se ponían a trabajar también las Cámaras de Comercio. ([CORPES XXI]: Onda Cero (oral), s.21)

b. Lola se puso también a trabajar en el restaurante y era la encargada del comedor. ([CORPES XXI]: Bas, Juan, La cuenta atrás, s.21)

Así pues, el análisis de la evolución formal de las perífrasis causativa e incoativa con poner permite formular dos conclusiones intermedias. Primero, ambas construcciones en las que poner funciona como un verbo auxiliar que incide en un infinivo subordinado se han desarrollado a partir del uso locativo original del verbo, y esto de modo paralelo pero a un ritmo diferente. La 
evolución paralela (y no consecutiva) de las dos construcciones, que ya existían ambas en el siglo 13 (cf. supra Tabla 2), resulta ser un primer argumento en contra del modelo desarrollado en la Figura 1, según el cual el uso causativo se hubiera originado antes del uso incoativo.

Segundo, el estudio de la evolución morfosintáctica de poner también nos ha revelado que la perífrasis causativa parece ser menos gramaticalizada que la incoativa. Su frecuencia aumenta paulatinamente con el tiempo, a un ritmo mucho más lento que el uso incoativo cuya evolución se caracteriza por una subida bastante rápida. Además, la perífrasis incoativa presenta un grado de incorporación mayor. En lo que sigue, examinaremos cómo las construcciones se han desarrollado semánticamente.

\section{Sección 6: Evolución semántica de las perífrasis causativas e incoativas con poner}

\subsection{Hipótesis}

Siguiendo el esquema de movimiento causado (cf. Figura 2), la construcción locativa prototípica expresada con poner implica un sujeto $\mathrm{SN}_{1}$ humano, un objeto $\mathrm{SN}_{2}$ inanimado y un verbo de colocación dinámico y transitivo (Pauwels 1995). A su vez, una construcción causativa prototípicamente consiste en un $\mathrm{SN}_{1}$ animado que actúa sobre un $\mathrm{SN}_{2}$ animado para hacerle realizar un evento dinámico (Shibatani 1975). Un esquema comparable vale para el uso incoativo prototípico, donde un solo participante entra en escena: un sujeto $\mathrm{SN}_{1}$ animado se pone a efectuar un evento dinámico. Así, en la literatura se asume que [ponerse a + INF] implica necesariamente un esfuerzo y cierta decisión o voluntad por parte del sujeto (8a) y suele combinarse con infinitivos dinámicos, de preferencia durativos que expresan actividades o realizaciones, pero tienden a rechazar infinitivos estáticos (8b) ('stative constraint' según Lamiroy 1987; ver también Carrasco Gutiérrez et al. 2006, Gómez Torrego 1988, Aparicio et al. 2014). 
(8) a. Después de casarse, *se puso a engordar sin darse cuenta. (Carrasco Gutiérrez et al. 2006: 221)

b. *Se pone a ser de noche. (Carrasco Gutiérrez et al. 2006: 222)

Ahora bien, como es bien sabido, un grado más alto de productividad de una construcción coincide con un aumento de la frecuencia de los tipos semánticos ('types') de la construcción, y con un incremento de su alcance colocacional (Barðdal 2008, Perek en prensa). Por ende, cuanto más la construcción se gramaticaliza, más se hace productiva (Traugott y Trousdale 2013) y más incluye esquemas semánticos menos prototípicos. Con el fin de verificar este planteamiento para la evolución del uso de las perífrasis, se examinan más en detalle las propiedades semánticas de sus constituyentes principales, a saber la animacidad del sujeto principal, y en la causativa del sujeto subordinado (4.2), así como el tipo de infinitivo subordinado (4.3).

\subsection{Animacidad sujeto principal $\mathrm{SN}_{1}$ y sujeto subordinado $\mathrm{SN}_{2}$}

Clasificamos los participantes sujeto según su capacidad o no de causar un cambio de estado, por lo cual los referentes animados (humanos, animales) se oponen a los inanimados (concretos y abstractos).

Primero, la Tabla 5 recoge la distribución histórica del tipo semántico del sujeto principal para ambas perífrasis.

Tabla 5: Evolución semántica sujeto principal

\begin{tabular}{|c|c|c|c|c|c|c|c|c|c|c|c|c|}
\hline \multirow{3}{*}{$\begin{array}{c}\text { perífrasis } \\
\mathrm{s} .\end{array}$} & \multicolumn{6}{|c|}{ causativa } & \multicolumn{6}{|c|}{ incoativa } \\
\hline & \multicolumn{2}{|c|}{ animado } & \multicolumn{2}{|c|}{ inanimado } & \multicolumn{2}{|c|}{ total } & \multicolumn{2}{|c|}{ animado } & \multicolumn{2}{|c|}{ inanimado } & \multicolumn{2}{|c|}{ total } \\
\hline & $\#$ & $\%$ & $\#$ & $\%$ & $\#$ & $\%$ & \# & $\%$ & $\#$ & $\%$ & $\#$ & $\%$ \\
\hline 13 & 19 & 100 & 0 & 0 & 19 & 100 & 7 & 100 & 0 & 0 & 7 & 100 \\
\hline 15 & 126 & 98,4 & 2 & 1,6 & 128 & 100 & 112 & 97 & 3 & 3 & 115 & 100 \\
\hline 17 & 269 & 98,5 & 4 & 1,5 & 273 & 100 & 195 & 97,5 & 5 & 2,5 & 200 & 100 \\
\hline 19 & 322 & 98,5 & 5 & 1,5 & 327 & 100 & 194 & 97 & 6 & 3 & 200 & 100 \\
\hline 21 & 511 & 90,9 & 51 & 9,1 & 562 & 100 & 187 & 93,5 & 13 & 6,5 & 200 & 100 \\
\hline
\end{tabular}

Como se refleja en la Tabla 5, la construcción causativa al inicio se documenta únicamente con sujetos animados dotados de intención (9). Comprobamos a partir del siglo 15 la aparición y el 
incremento paulatino de construcciones causativas con un sujeto inanimado. Así en (10) un obstáculo (embarazo) hizo que Diego de Sant Pedro no hiciera lo que tenía que hacer (encontrar la Pasión del Redentor). Los casos con sujeto inanimado muestran que ya en documentaciones antiguas, la perífrasis causativa con poner se extiende al campo de la causación indirecta. ${ }^{9}$ En su uso actual, la frecuencia de sujetos animados sigue siendo dominante (11a), pero se destacan varios ejemplos con sujetos inanimados, concretos (11b) y abstractos (11c), que no controlan la acción realizada.

(9) Badiza era fijo de estrellero \& pusol el padre a leer como dixiemos ([CORDE]: Alfonso X, General Estoria. Cuarta parte, s.13)

(10) Una devota monja rogó a Diego de Sant Pedro que trobasse la Passión de Nuestro Redentor, a la cual él quería tanto que todo su pensamiento era en qué y cómo la havía de servir, y aunque insufficientia grand embarazo le pusiesse a no fazello, forzando su voluntad, por su mandado hovo de trobar la dicha Passión. ([CORDE]: San Pedro, Diego de, Pasión trovada, s.15)

(11) a. Como ejercicio el maestro solía poner a sus alumnos a realizar largas y monótonas sumas de números como: "1198 + $1396+1594$..." etc. ([CORPES XXI]: Rodríguez Fraile, Juan, Cuaderno de Materiales, s.21)

b. Give me the 70s puso a bailar a medio país. ([CORPES XXI]: El Norte de Castilla, s.21)

c. Al ser una disciplina que pone a trabajar todos los músculos del cuerpo, los resultados se apreciarán en tus piernas, tus brazos, tu abdomen y tus glúteos. ([CORPES XXI]: Ceño ElieJoseph, Mónica, Desnudas. Aprende a quererte tal como eres, s.21)

La misma tendencia se observa en la perífrasis incoativa. Los pocos ejemplos atestiguados en el siglo 13 se construyen todos con un sujeto animado (12). A partir del siglo 15 se introducen en el

\footnotetext{
${ }^{9}$ Por 'causación directa' se entiende que el sujeto principal actúa directamente sobre el tema causado mientras que en la 'causación indirecta' no tiene control inmediato sobre él (Shibatani 1975; Enghels y Roegiest 2013: 515). Cuando el sujeto principal (causante) es inanimado el acto causativo solo puede ser indirecto.
} 
paradigma los sujetos inanimados (13a), cuya frecuencia aumenta ligeramente y se mantiene en el uso contemporáneo de la perífrasis (13b). Además, solo en el subcorpus del siglo 21 se observa la posibilidad de la construcción de incorporar sujetos impersonales (ausentes en el corpus entero de la perífrasis causativa). El ejemplo (14) - así como todos los ejemplos con sujetos inanimados - ilustra claramente que el significado incoativo está vehiculado por la construcción entera [ponerse + infinitivo] y que se ha suprimido el lazo con el uso locativo original del verbo [*X se pone en el proceso de llover].

(12) [...] ponte a dezir le que uiniesse luego a tierra de Costantinopla a ayudar los assacar del Jmperio a Alexi el adelantado ([CORDE]: Anónimo, Gran Conquista de Ultramar. Ms. 1187 BNM, s.13)

(13) a. En esto es entendido moralmente que la avididat humana es de tancta actoridat entre las otras que, cuando derechamente se pone a las inclinar a algún propósito, la siguen plazenteramente e concorde. ([CORDE]: Villena, Enrique de, Traducción y glosas de la Eneida. Libros I-III, s.15) b. Los años se pusieron a pasar más y más rápido. ([CORPES XXI]: Vidal-Folch, Ignacio, Noche sobre noche, s.21)

(14) No obstante, abogó por "retejar la casa" antes de que "se ponga a llover". ([CORPES XXI]: $A B C$, s.21)

Luego, recordamos que de acuerdo con el modelo propuesto como hipótesis de trabajo (Figura 1) y la definición de la causativa prototípica (cf. sección 6.1), la construcción causativa se asocia prototípicamente con un participante subordinado humano en quien el sujeto principal puede actuar con el fin de hacerle realizar un proceso. En esta línea de ideas, la Tabla 6 sintetiza las frecuencias de la naturaleza semántica del sujeto subordinado $\mathrm{SN}_{2}$ para el uso causativo. 
Tabla 6: Evolución semántica sujeto subordinado

\begin{tabular}{|c|c|c|c|c|c|c|}
\hline \multicolumn{7}{|c|}{ causativa } \\
\hline \multirow{2}{*}{ s. } & \multicolumn{2}{|c|}{ animado } & \multicolumn{2}{c|}{ inanimado } & \multicolumn{2}{|c|}{ total } \\
\cline { 2 - 8 } & $\#$ & $\%$ & $\#$ & $\%$ & $\#$ & $\%$ \\
\hline 13 & 14 & 73,7 & 5 & 26,3 & 19 & 100 \\
\hline 15 & 34 & 26,6 & 94 & 73,4 & 128 & 100 \\
\hline 17 & 29 & 10,6 & 244 & 89,4 & 273 & 100 \\
\hline 19 & 31 & 9,5 & 296 & 90,5 & 327 & 100 \\
\hline 21 & 191 & 34 & 371 & 66 & 562 & 100 \\
\hline
\end{tabular}

Los datos cuantitativos confirman que en el siglo 13, los sujetos subordinados animados claramente dominan (Moisén en 15a), aunque alternan ya con inanimados (la leche en 15b). La proporción de los contextos con sujeto subordinado inanimado incluso llega a predominar a partir del siglo 15 (16a). Si bien muestra una tendencia a la baja en el siglo 21 (16b), nunca desciende del $50 \%$ del total de construcciones causativas.

(15) a. Agora dexamos aquí estas razones e diremos de las otras cosas que contecieron en aquellos días que avedes oído que pusieron Moisén con los otros fijos de Israel en ir de la ribera del mar Vermejo a Rafadín. ([CORDE]: Alfonso X, General Estoria. Primera parte, s. 13)

b. Si no, tomen lech d'asnas prietas e mezclen con ella olyo de sísamo, e pónganla a escalentar sobr'el fuego; [...]. ([CORDE]: Toledo, Abraham de, Moamín. Libro de los animales que cazan, s. 13)

(16) a. E vido la opinión de los antyguos en el poner del vacuo, e quál fue la intençión de los que ge lo pusyeron e cómo lo provavan e los errores de los que ponían un cuerpo sólido penetrar las dimensyones de otro. ([CORDE]: Torre, Alfonso de la, Visión deleytable, s.15)

b. Mi padre [...] puso a trabajar los limpiaparabrisas a velocidad frenética. ([CORPES XXI]: Yanes, Javier, Si nunca llego a despertar, s.21)

Así pues, ambas construcciones se caracterizan por la ampliación del paradigma de sujetos principales, y ambas construcciones se extienden semánticamente entre los siglos 13 y 21, con un cambio principal entre el siglo 13 y 15 . Además, en el mismo periodo la perífrasis causativa con 
poner se abre a incorporar más fácilmente sujetos subordinados inanimados ${ }^{10}$. En otras palabras, si bien en sus características formales la perífrasis incoativa es más gramaticalizada que la causativa, con un uso más auxiliarizado de poner (sección 5), la productividad (semántica) de ambas construcciones se extiende gradualmente.

\subsection{Dinamicidad del infinitivo}

De igual manera es posible clasificar los infinitivos según el grado de transferencia de energía que implican: alto (transitivos [TR] e inergativos [INERG]) o bajo (inacusativos [INAC] y copulativos [COP]) (Enghels 2007). De acuerdo con su definición básica (sección 6.1), las perífrasis causativa e incoativa suelen combinarse con infinitivos dinámicos, rechazando los infinitivos estáticos. La Tabla 7 permite verificar esta premisa.

Tabla 7: Evolución semántica infinitivo

\begin{tabular}{|c|c|c|c|c|c|c|c|c|c|c|c|c|c|c|c|c|c|c|c|c|}
\hline \multirow[b]{3}{*}{ s. } & \multicolumn{10}{|c|}{ causativa } & \multicolumn{10}{|c|}{ incoativa } \\
\hline & \multicolumn{2}{|c|}{ TR } & \multicolumn{2}{|c|}{ INERG } & \multicolumn{2}{|c|}{ INAC } & \multicolumn{2}{|c|}{$\mathrm{COP}$} & \multicolumn{2}{|c|}{ total } & \multicolumn{2}{|c|}{ TR } & \multicolumn{2}{|c|}{ INERG } & \multicolumn{2}{|c|}{ INAC } & \multicolumn{2}{|c|}{$\mathrm{COP}$} & \multicolumn{2}{|c|}{ total } \\
\hline & \# & $\%$ & \# & $\%$ & \# & $\%$ & \# & $\%$ & \# & $\%$ & \# & $\%$ & \# & $\%$ & \# & $\%$ & \# & $\%$ & \# & $\%$ \\
\hline 13 & 12 & 63,2 & 5 & 26,3 & 2 & 10,5 & 0 & 0 & 19 & 100 & 4 & 57,1 & 1 & 14,3 & 2 & 28,6 & 0 & 0 & 7 & 100 \\
\hline 15 & 52 & 40,6 & 9 & 7 & 67 & 52,3 & 0 & 0 & 128 & 100 & 91 & 79,1 & 21 & 18,3 & 3 & 2,6 & 0 & 0 & 115 & 100 \\
\hline 17 & 31 & 11,4 & 6 & 2,2 & 236 & 86,4 & 0 & 0 & 273 & 100 & 147 & 73,5 & 48 & 24 & 2 & 1 & 3 & 1,5 & 200 & 100 \\
\hline 19 & 22 & 6,7 & 8 & 2,4 & 297 & 90,8 & 0 & 0 & 327 & 100 & 133 & 66,5 & 64 & 32 & 2 & 1 & 1 & 0,5 & 200 & 100 \\
\hline 21 & 60 & 10,7 & 142 & 25,3 & 360 & 64,1 & 0 & 0 & 562 & 100 & 97 & 48,5 & 96 & 48 & 6 & 3 & 1 & 0,5 & 200 & 100 \\
\hline
\end{tabular}

Atendiendo a la Tabla 7, se comprueba que en el siglo 13 la construcción causativa selecciona mayoritariamente infinitivos transitivos (17a) e inergativos (17b). Sin embargo, a partir del siglo 15 se observa un fuerte incremento de infinitivos inacusativos (18a), en detrimento de los infinitivos transitivos dinámicos. En el corpus del siglo 21, los infinitivos inacusativos constituyen la mayoría (18b).

\footnotetext{
${ }^{10}$ Estos hechos coinciden con los planteamientos de Heine (1993: 54): un proceso de gramaticalización y la desemantización que implica, conlleva un cambio de distribución. En la fase inicial (source) el sujeto típicamente tiene un referente humano y concreto, mientras que la fase final gramaticalizada (target) ya no implica necesariamente un sujeto humano o dotado de intención. Así, el verbo adquiere una distribución más larga y puede aparecer en más contextos diferentes conforme avanza en el proceso de gramaticalización.
} 
(17) a. Persseo fue bien criado \& bien aguardado.E t des que uino a tiempo que era ya pora ello. pusieron le a leer. \& apprendie muy bien. ([CORDE]: Alfonso X, General Estoria. Segunda parte, s.13)

b. Et dixo la muger : - ¿Quién te pone en fablar en lo que non sabes si será o non? ([CORDE]: Anónimo, Calila e Dimna, s.13)

(18) a. Como vees la barua de tu vezino pelar, pone la tuya a remogar, e quando cae la vaca, aguza el cuchillo. ([CORDE]: Anónimo, Cancionero de Juan Fernández de Íxar, s. 15)

b. Cagondiós, que sin tiempo que perder el Roque le metió un culatazo en la cabeza que le puso a sangrar como un marrano. ([CORPES XXI]: Montero Glez, Manteca colorá, s.21)

Por su parte, de la Tabla 7 se desprende que en la construcción incoativa también prevalecen en el siglo 13 los infinitivos transitivos (19). No obstante, contrariamente al cambio semántico observado en la perífrasis causativa, los infinitivos transitivos (20a) e inergativos (20b) se mantienen dominantes hasta el siglo 21. Aun más, los transitivos tienden a bajar en favor de los inergativos, que llegan a rozar el $50 \%$ en el siglo 21 . Al revés, la frecuencia de los inacusativos baja notablemente a partir del siglo 15 (21) y los infinitivos copulativos existen pero constituyen una minoría (22).

(19) Badiza era fijo de estrellero \& pusol el padre a leer como dixiemos. ([CORDE]: Alfonso X, General Estoria. Cuarta parte., s. 13)

(20) a. Joa se quedó en casa de su tío y, como tantas otras veces antes, se pusieron a hojear los viejos álbumes de fotos para ver a sus padres de jóvenes. ([CORPES XXI]: Torres Blandina, Alberto, Niños rociando gato con gasolina, s.21)

b. [...] mi papá se sentaba solo en lo más oscuro del bodegón y mientras bebía vino blanco fresquito, sin convidar ni hablar con nadie, se ponía a cavilar. ([CORPES XXI]: Serra Manzanares, Berta, Los ojos del huracán, s.21) 
(21) Quiere decirse que el paro disminuía cuando los salarios monetarios se ponían a aumentar más deprisa por efecto de la inflación y viceversa. ([COPRES XXI]: Schwartz, Pedro, La economía explicada a Zapatero y a sus sucesores. En dos tardes, s. 21)

(22) Después de limpiar un año seguido los váteres aquellos te diré que cuando las tías se ponen a ser guarras no hay quien las haga sombra. ([CORPES XXI]: Lindo, Elvira, Una palabra tuya, s. 21)

En lo relativo al grado de dinamicidad, en general, los infinitivos transitivos presentan el grado más elevado de dinamicidad, seguidos de los infinitivos inergativos, los inacusativos y los infinitivos copulativos. Así, la división cuadripartita puede generalizarse, calificando los infinitivos transitivos e inergativos como dinámicos, y los inacusativos y los copulativos como no (o menos) dinámicos. Desde esta perspectiva, resulta que la construcción incoativa con poner auxiliar muestra una predilección marcada por los eventos dinámicos, tal y como lo describen estudios anteriores (Carrasco Gutiérrez et al. 2006, Gómez Torrego 1988, Aparicio et al. 2014). Al revés, en su uso como auxiliar causativo, poner selecciona más frecuentemente los eventos menos dinámicos, al lado de los dinámicos.

En suma, del estudio semántico podemos concluir que las perífrasis causativa e incoativa han subido una extensión semántica considerable a lo largo de los diferentes cortes cronológicos: en ambas construcciones comprobamos que el elenco de sujetos principales y subordinados, e infinitivos diferentes se incrementa, permitiendo a participantes y eventos menos prototípicos de establecerse en el paradigma. Sin embargo, esta expansión - ante todo en cuanto al tipo de evento causado - parece haber sido más importante en el desarrollo del uso causativo que en el uso incoativo.

Por un lado, este resultado resulta sorprendente, dado que el análisis de las propiedades formales apuntaba a que la construcción incoativa era más gramaticalizada, incitando un mayor grado de incorporación sintáctica con el infinitivo subordinado que le acompaña. De este modo, 
se hubiera esperado igualmente una gama más amplia de contextos semánticos en los que puede aparecer. Por el otro lado, el resultado no desvía de lo esperado: si ponerse provoca más incorporación sintáctica con el infinitivo que sigue, este auxiliar incoativo le impone al infinitivo también más restricciones semánticas. Al revés, considerando el grado más bajo de incorporación en la construcción causativa, la cohesión sintáctica entre el auxiliar poner y su infinitivo parece menos sólida, lo que conlleva entonces un patrón semántico más variado del complemento infinitivo.

\section{Sección 7: Discusión}

El presente estudio de caso ha propuesto arrojar luz sobre la evolución histórica de las construcciones causativa e incoativa con poner en español. El objetivo no solo ha sido (a) examinar el cómo y el cuándo de la aparición de ambas construcciones, sino también (b) determinar en qué medida poner se comporta como verbo auxiliar en ambas perífrasis. Al mismo tiempo, los resultados del análisis formal y semántico permiten averiguar las implicaciones más importantes del modelo propuesto en la Figura 1 para la evolución de poner en español.

Primero, el modelo implica que el uso causativo de poner (y mettre) tendría que haber emergido antes del uso incoativo. Sin embargo, la sección 3 atestigua un desarrollo paralelo más bien que consecutivo de ambas construcciones. De hecho, es verdad que en el corpus del siglo 13 se encuentran más ejemplos de la perífrasis causativa que de la incoativa, pero ambos usos parecen haberse desarrollado simultáneamente. Además, el corpus ya procura ejemplos (aunque numéricamente muy limitados) de la incoativa.

La segunda implicación concierne la preposición que precede al infinitivo en las perífrasis, que según el modelo desarrollado, siempre sería $a$. No obstante, los datos del corpus sugieren más bien que haya tenido lugar una competición entre construcciones con la preposición en, $a$ y 
la preposición 'cero' sobre todo en los siglos tempranos (s.13-15). Así pues, esta segunda implicación tampoco se verifica en el corpus estudiado.

Tercero, el modelo se basa en el esquema prototípico con un $\mathrm{SN}_{1}$ humano, un $\mathrm{SN}_{2}$ humano y un infinitivo transitivo y dinámico. Si bien al inicio, este esquema aparece con más frecuencia, se comprueba para ambos usos una extensión gradual hacia participantes inanimados e impersonales menos prototípicos. Asimismo, en la evolución del infinitivo hemos podido observar una extensión hacia infinitivos menos dinámicos (inacusativos), sobre todo en la perífrasis causativa. La perífrasis incoativa, en cambio, siempre parece inclinarse hoy en día por los infinitivos prototípicos dinámicos (transitivos e inergativos).

Finalmente, del modelo se deduce que los contextos puente (bridging contexts), que constituyen una etapa clave en el proceso de gramaticalización, se corresponderían con aquellos casos en los que un complemento de lugar y un complemento infinitivo concurren [poner a alguien en un lugar a hacer algo -> poner a alguien a hacer algo]. El corpus documenta estos contextos puente, aunque solo se trata de un número limitado de ejemplos (el 83/6083 o el 1.4\% del corpus en su totalidad), como muestra la Tabla 8.

Tabla 8: Evolución frecuencia contextos puente

\begin{tabular}{|c|c|c|c|}
\hline \multicolumn{4}{|c|}{$\mathrm{V}+\mathrm{NP} 2+[\mathrm{en} \mathrm{Loc]}+[\mathrm{a}$ INF] } \\
\hline s. & $\#$ & total \# & $\%$ \\
\hline 13 & 2 & 27 & 7,4 \\
\hline 15 & 17 & 248 & 6,9 \\
\hline 17 & 26 & 923 & 2,8 \\
\hline 19 & 18 & 1394 & 1,3 \\
\hline 21 & 20 & 3491 & 0,6 \\
\hline
\end{tabular}

Los subcorpus correspondientes a los cinco cortes cronológicos proporcionan ejemplos del tipo $[\mathrm{V}+\mathrm{NP} 2+[$ en Loc $]+[$ a INF] $](23 \mathrm{a}-\mathrm{d})$. Su frecuencia disminuye considerablemente, pero aún se construyen en el siglo 21 (24a-b). Sin embargo, la escasez de este tipo de ejemplos en el corpus no nos permite confirmar su papel como contexto puente en el proceso de gramaticalización de 
poner al pasar de verbo locativo a verbo auxiliar causativo/incoativo. Así, la última implicación del modelo solo se corrobora parcialmente.

(23) a. si ponen $\$ a guardar algun pez assado de qual natura quier que sea porque aquel maniar recibe en si olor mala \& fazse tossico ([CORDE]: Alfonso X, Lapidario, s. 13)

b. [...] despues pusose por la çibdad a partyr las viandas. ([CORDE]: Anónimo, Traducción de la historia del noble Vespasiano, s. 15.)

c. Se puso en un lugar alto a ver la batalla. ([CORDE]: López, Diego, Declaración magistral sobre las emblemas de Andrés Alciato, s. 17)

d. Nos han puesto en la orilla a contemplar tempestades ([CORDE]: Unamuno, Miguel de, Carta a Ganivet II, s. 19)

(24) a. Hay que ver lo que te gustaba ponerte a mi lado a observarme pintar. ([CORPES XXI]: Díaz, María Paz, Amor en Florencia, s. 21)

b. Oleh Blokhin le pondrá sobre el terreno de juego a liderar a su equipo porque aún tiene el potencial de ganar él un partido“ ([CORPES XXI]: El Mundo, s. 21)

En fin, el único argumento que aboga en favor del modelo propuesto en la Figura 1, es el que los contextos de convencionalización solo aparecen en siglos posteriores y nunca en los siglos 13 o 15. En dichos contextos, poner parece haberse consolidado como verbo auxiliar y concurre con su uso locativo básico (concreto o abstracto) o con otros usos en la misma oración.

a. mas oyendo mi amo el ruido, salió a la calle con su espada y daga, y en cuerpo se puso a ponerlos en paz. ([CORDE]: Castillo Solórzano, Alonso de, Lisardo enamorado, s.17)

b. Y yo le dije: "¡Señor! ¡Son las gallinas señor!... ¡se han puesto a poner como locas!... ¡icinco docenas de huevos!..." ([CORPES XXI]: La Ratonera, s.21)

Como consecuencia, la Figura 3 propone un modelo alternativo para la evolución de las perífrasis causativas e incoativas con poner, que igualmente se basa en los cuatro estadios de Heine (2002). 
Figura 3: Desarrollo perífrasis causativas e incoativas: modelo alternativo

\begin{tabular}{|c|c|c|c|}
\hline & Construcción & desarrollo períf. causativa & desarrollo períf. incoativa \\
\hline Fase 1 & \multicolumn{3}{|l|}{ en + LOC [locativa] } \\
\hline $\mathbf{a}$ & & Poner algo en un lugar & \\
\hline b & & Poner a alguien en un lugar & Ponerse en un lugar \\
\hline c (bridging context) & {$[e n+I N F]_{l o c}$} & $\begin{array}{l}\text { Poner a alguien en (el estado } \\
\text { de) una actividad/un evento }\end{array}$ & Ponerse en una actividad \\
\hline Fase 2 & \multicolumn{3}{|c|}{ competición $[e n+I n f]_{l o c} /[a+I N F]_{m e t a} /[0+I N F]$} \\
\hline \multirow{2}{*}{$\begin{array}{l}\text { Fase } 3 \\
(\text { switch context })\end{array}$} & \multicolumn{3}{|c|}{$[a+$ Inf] vence + extinción $[e n+$ Inf $] /[0+I N F]$} \\
\hline & {$[a+I N F]_{m e t a}$} & Poner a alguien a hacer algo' & Ponerse a hacer algo \\
\hline \multirow{2}{*}{$\begin{array}{l}\text { Fase } 4 \\
\text { (conventionalization) }\end{array}$} & \multicolumn{3}{|c|}{ Expansión de la construcción a otros contextos } \\
\hline & & $\begin{array}{l}\text {-menos incorporación } \\
\text {-poner: 'semi-auxiliar'? } \\
\text {-expansión semántica } \\
\text {-menos gramaticalización? }\end{array}$ & $\begin{array}{l}\text {-más incorporación } \\
\text {-poner: auxiliar? } \\
\text {-menos expansión semántica } \\
\text {-más gramaticalización? }\end{array}$ \\
\hline
\end{tabular}

En concreto, el esquema alternativo propone que las dos perífrasis se han desarrollado de manera paralela antes que consecutiva. Poner originalmente entra en la construcción locativa con tres argumentos (Fase 1a). El modelo sostiene que los contextos puente clave son precisamente aquellos en los que el complemento locativo se deja interpretar como locativo abstracto, esto es, como un evento o una actividad en la que el tema o sujeto subordinado (en la causativa) o el agente (en la incoativa) se puede 'poner' metafóricamente (Fase 1c). Luego se observa un período de competición entre la construcción con interpretación locativa-eventiva (expresada con la preposición en) y otra con una interpretación orientada hacia la meta (expresada con la preposición a) (Fase 2). Finalmente, la construcción con interpretación semántica orientada hacia la meta (de efectuar el proceso expresada por el infinitivo) predomina y la construcción con en acaba por caer en desuso (Fase 3). En la fase de convencionalización, las construcciones causativas y las incoativas se extienden a otros contextos, en una medida diferente (Fase 4).

La perífrasis causativa da muestras de un grado menor de incorporación sintáctica, por lo cual poner presenta un grado de auxiliaridad más bajo. Por consiguiente impone menos restricciones al complemento infinitivo subordinado que se extiende a contextos semánticos más diversos. Al revés, en la perífrasis incoativa comprobamos un grado mayor de incorporación, por lo cual se 
imponen más restricciones sobre el infinitivo subordinado, y se observa una productividad semántica más limitada.

\section{Referencias}

\section{Corpus}

Real Academia Española: Banco de datos (CORDE) [en línea]. Corpus diacrónico del español. $<$ http://corpus.rae.es/cordenet.html>

Real Academia Española: Banco de datos (CORPES XXI) [en línea]. Corpus del Español del Siglo XXI (CORPES). <http://web.frl.es/CORPES/view/inicioExterno.view>

\section{Obras citadas}

Aparicio, Juan, Coll-Florit, Marta y Castellón, Irene, 2014. 'Perífrasis incoativas: aproximación cognitiva y estudio de corpus', Sintagma, 26: 73-88.

Aparicio, Juan, 2016. Representación computacional de las perífrasis aspectuales: de la cognición a la computación (Barcelona: Universidad de Barcelona).

Azofra Sierra, María Elena, 2009. Morfosintaxis histórica del español: de la teoría a la práctica (Madrid: UNED).

Barðdal, Jóhanna, 2008. Productivity: Evidence from case and argument structure in Icelandic (Amsterdam: John Benjamins).

Bergs, Alexander y Diewald, Gabriele, 2008. Constructions and language change (Berlin: de Gruyter).

Borillo, André, 2005. 'Peut-on identifier et caractériser les formes lexicales de l'aspect en français?', en Les Périphrases Verbales, ed. Hava Bat-Zeev Shyldkrot y Nicole Le Querler (Amsterdam/Philadelphia: John Benjamins), pp. 83-102. 
Bosque, Ignacio y Demonte, Violeta, 1999. Gramática descriptiva de la lengua española, II (Madrid: Espasa-Calpe).

Cano Aguilar, Rafael, 1977-78. 'Cambios en la construcción de los verbos en castellano medieval', Archivum, XVII-XVIII: 335-379.

Carrasco Gutiérrez, Ángeles et al., 2006. Diccionario de perífrasis verbales (Madrid: Gredos).

Cifuentes Honrubia, José Luis, 1999. Sintaxis y semántica del movimiento (Alicante: Instituto de Cultura Juan Gil-Albert).

Comer, Marie, Enghels, Renata y Vanderschueren, Clara, 2015. 'De verbos de colocación a pseudo-copulativos: procesos de gramaticalización en los cuasi-sinónimos poner/meter y pôr/meter en español y en portugués', Zeitschrift für romanische Philologie, 131.2: 355-382.

Correas, Gonzalo, 1625. Arte de la lengua española castellana (Madrid: CSIC (1954)).

Enghels, Renata, 2007. Les Modalités de perception visuelle et auditive: différences conceptuelles et répercussions sémantico-syntaxiques en espagnol et en français (Tübingen: Niemeyer).

Enghels, Renata y Roegiest, Eugeen, 2013. 'Dejar: entre verbo causativo y verbo de control', Bulletin of Hispanic Studies, 90.5: 505-522.

Fauconnier, Gilles, 1983. 'Generalized Union', en Problems in syntax, ed. Liliane Tasmowski y Dominique Willems (Gent: Plenum), pp. 195-229.

Fischer, Olga, 2007. Morphosyntactic change. Functional and Formal Perspectives (New York: Oxford University Press).

Fogsgaard, Lene, 2001. 'Algunas perífrasis incoativas con A + infinitivo', Estudios de Lingüística, 15: 5-35.

Fogsgaard, Lene. 2002. Algunas perífrasis aspectuales del español (Alicante: Universidad de Alicante). 
Garachana Camarero, Mar, 2016. 'Restricciones léxicas en la gramaticalización de las perífrasis verbales', RILCE: Revista de filología hispánica, 32.1: 136-158.

Gisborne, Nikolas y Patten, Amanda, 2011. 'Constructions and grammaticalization', en The Oxford handbook of grammaticalization, ed. Heiko Narrog y Bernd Heine (Oxford: Oxford University Press), pp. 92-104.

García Fernández, Luis, 2012. Las perífrasis verbales en español (Barcelona: Castalia).

García González, Javier, 1992. Perífrasis verbales (Madrid: Sociedad General Española de Librería).

Goldberg, Adele, 1995. Constructions: a construction grammar approach to argument structure (Chicago: University of Chicago Press).

Gómez Torrego, Leonardo, 1988. Perífrasis verbales (Madrid: Arco Libros).

Gómez Manzano, Pilar, 1992. Perífrasis verbales con infinitivo (valores y usos en la lengua hablada) (Madrid: Universidad Nacional de Educación a Distancia).

Heine, Bernd, 1993. Auxiliaries: cognitive forces and grammaticalization (New York: Oxford University Press).

Heine, Bernd, 2002. 'On the role of context in grammaticalization', en New Reflections on Grammaticalization, ed. Ilse Wischer y Gabriele Diewald (Amsterdam/Philadelphia: John Benjamins), pp. 83-102.

Ibarretxe, Iraide, 2012. 'Placement and removal events in Basque and Spanish', en Events of putting and taking: A crosslinguistic perspective, ed. Anetta Kopecka y Bhuvana Narasimhan (Amsterdam: John Benjamins), pp. 123-143.

Jansegers, Marlies, 2015. Hacia un enfoque múltiple de la polisemia. Un estudio empírico del verbo multimodal 'sentir'desde una perspectiva sincrónica y diacrónica (Gent: Universiteit Gent). 
Jansegers, Marlies y Enghels, Renata, 2013. 'De verbo de percepción a marcador de disculpa: la evolución diacrónica del verbo sentir en español', Revue de Linguistique Romane, 77.305: 139166.

Lamiroy, Béatrice, 1987. 'The complementation of aspectual verbs in French', Language, 63.2: 278-298.

Lamiroy, Béatrice, 1994. 'Les compléments nominaux dans une perspective typologique et la question de l'auxiliarité', Language, 115: 64-75.

Lamiroy, Béatrice, 1999. 'Auxiliaires, langues romanes et grammaticalisation', Langages, 135: $33-46$.

Lamiroy, Béatrice y De Mulder, Walter, 2011. 'Degrees of Grammaticalization Across Languages', en The Oxford handbook of grammaticalization, ed. Heiko Narrog y Bernd Heine (Oxford: Oxford University Press), pp. 302-317.

Llorente Vigil, Covadonga, 1999. Las perífrasis verbales (Salamanca: Ediciones Colegio de España).

Pauwels, Paul, 1995. 'Levels of Metaphorization. The Case of Put', en By word of mouth. metaphor, metonymy and linguistic action in a cognitive perspective, ed. Louis Goossens et al. (Amsterdam/Philadelphia: John Benjamins), pp. 125-158.

Penny, Ralph, 2012. Gramática histórica del español (Barcelona: Ariel).

Perek, Florent, en prensa. 'Using distributional semantics to study syntactic productivity in diachrony: A case study', Linguistics.

Real Academia Española y Asociación de Academias de la Lengua Española, 2009. Nueva gramática de la lengua española. Morfología y sintaxis (Madrid: Espasa).

Shibatani, Mayayoshi, 1975. A linguistic study of causative constructions (Bloomington: Indiana University Linguistics Club). 
Thompson, Sandra A. y Mulac, Anthony, 1991. 'The discourse conditions for the use of the complementizer that in conversational English', Journal of pragmatics, 15: 237-251.

Traugott, Elizabeth y Dasher, Richard, 2002. Regularity in semantic change (Cambridge: Cambridge University Press).

Traugott, Elizabeth y Trousdale, Graeme, 2013. Constructionalization and constructional change (Oxford: Oxford University Press).

Trousdale, Graeme, 2008. 'Constructions in grammaticalization and lexicalization. Evidence from the history of a composite predicate construction in English', en Constructional approaches to English grammar, ed. Graeme Trousdale y Nikolas Gisborne (Berlin: de Gruyter), pp. 33-67.

Trousdale, Graeme, 2010. 'Issues in constructional approaches to grammaticalization in English', en Grammaticalization. Current views and issues, ed. Katherina Stathi, Elke Gehweiler y Ekkehard König (Amsterdam: John Benjamins), pp. 51-72.

Vergara Wilson, Damián, 2009. 'From 'remaining' to 'becoming' in Spanish: The role of prefabs in the development of the construction 'quedar(se) + adjective', en Formulaic Language, ed. Roberta Corrigan et al. (Philadelphia: John Benjamins), pp. 273-295.

Verroens, Filip, 2011. La construction inchoative se mettre à: syntaxe, sémantique et grammaticalisation (Gent: Universiteit Gent). 